\title{
Early initiation of low-dose corticosteroid therapy in the management of septic shock: a retrospective observational study
}

\author{
Hye Yun Park', Gee Young Suh', Jae-Uk Song ${ }^{1}$, Hongseok Yoo' Ik Joon Jo², Tae Gun Shin², So Yeon Lim', \\ Sookyoung $\mathrm{Woo}^{3}$ and Kyeongman Jeon ${ }^{1 *}$
}

\begin{abstract}
Introduction: The use of low-dose steroid therapy in the management of septic shock has been extensively studied. However, the association between the timing of low-dose steroid therapy and the outcome has not been evaluated. Therefore, we evaluated whether early initiation of low-dose steroid therapy is associated with mortality in patients with septic shock.
\end{abstract}

Methods: We retrospectively analyzed the clinical data of 178 patients who received low-dose corticosteroid therapy for septic shock between January 2008 and December 2009. Time-dependent Cox regression models were used to adjust for potential confounding factors in the association between the time to initiation of low-dose corticosteroid therapy and in-hospital mortality.

Results: The study population consisted of 107 men and 71 women with a median age of 66 (interquartile range, 54 to 71 ) years. The 28 -day mortality was $44 \%$ and low-dose corticosteroid therapy was initiated within a median of 8.5 (3.8 to 19.1) hours after onset of septic shock-related hypotension. Median time to initiation of low-dose corticosteroid therapy was significantly shorter in survivors than in non-survivors ( 6.5 hours versus 10.4 hours; $P=$ 0.0135). The mortality rates increased significantly with increasing quintiles of time to initiation of low-dose corticosteroid therapy ( $P=0.0107$ for trend). Other factors associated with 28-day mortality were higher Simplified Acute Physiology Score (SAPS) $3(P<0.0001)$ and Sequential Organ Failure Assessment (SOFA) scores $(P=0.0007)$, dose of vasopressor at the time of initiation of low-dose corticosteroid therapy $(P<0.0001)$, need for mechanical ventilation $(P=0.0001)$ and renal replacement therapy $(P<0.0001)$, while the impaired adrenal reserve did not affect 28 -day mortality ( $81 \%$ versus $82 \%$; $P=0.8679$ ). After adjusting for potential confounding factors, the time to initiation of low-dose corticosteroid therapy was still significantly associated with 28-day mortality (adjusted odds ratio (OR) $1.025,95 \%$ confidence interval $(C I) 1.007$ to $1.044, P=0.0075$ ). The early therapy group (administered within 6 hours after the onset of septic shock, $n=66$ ) had a 37\% lower mortality rate than the late therapy group (administered more than 6 hours after the onset of septic shock, $n=112)(32 \%$ versus $51 \%, P=0.0132)$.

Conclusions: Early initiation of low-dose corticosteroid therapy was significantly associated with decreased mortality.

\section{Introduction}

Septic shock is one of the most common causes of death in patients admitted to the ICU [1,2]. Despite advances in early and appropriate antibiotic therapy, initial resuscitation, source control, and organ support,

\footnotetext{
* Correspondence: kjeon@skku.edu

'Division of Pulmonary and Critical Care Medicine, Department of Medicine, Samsung Medical Center, Sungkyunkwan University School of Medicine, 81

Irwon-ro, Gangnam-gu, Seoul, 135-710, Republic of Korea

Full list of author information is available at the end of the article
}

septic shock remains a major source of short-term and long-term morbidity and mortality [3]. Although multiple adjunctive therapies for septic shock have been developed and studied in clinical trials, few of these methods have demonstrated improvements in survival [4]. Corticosteroid treatment has been studied extensively as adjunctive therapy in patients with septic shock for over 40 years. Initial trials investigating a short course of high-dose corticosteroid as an anti- 
inflammatory regimen found no evidence of a survival benefit $[5,6]$. In contrast, more recent trials demonstrated that a longer course ( $\geq 5$ days) of low-dose corticosteroid resulted in shock reversal [7] and improved mortality rate $[8,9]$. Based primarily on a large randomized, multicenter, controlled study performed by Annane et al. [9], the Surviving Sepsis Campaign guidelines recommend the use of low-dose corticosteroid in patients with septic shock requiring vasopressors despite fluid replacement [3]. Recently, however, the Corticosteroid Therapy of Septic Shock (CORTICUS) study by Sprung et al. [10] did not demonstrate an improvement in mortality rate after low-dose corticosteroid therapy in patients with septic shock. The contradictory findings of these two large multicenter studies generated controversy regarding the appropriateness of corticosteroid therapy in patients with septic shock.

Although a number of factors may have accounted for the differences in the results of these two large multicenter studies, the difference in the time window of enrollment should be considered [11]. Annane et al. initially enrolled patients in the study within three hours of the onset of shock, and this time window from the onset of septic shock to randomization was increased to eight hours [9]. In contrast, in the CORTICUS study, patients were required to undergo randomization within 24 hours after the onset of septic shock, and this time window was subsequently increased to 72 hours [10]. Therefore, it is probable that the benefit of low-dose corticosteroid therapy may diminish with a delay in instituting the treatment [12]. However, there have been no reports regarding the association between the timing of corticosteroid therapy and mortality in patients with septic shock. Therefore, we performed a retrospective analysis of the clinical data from patients who received low-dose corticosteroid therapy for septic shock to determine whether early initiation of this therapy is associated with decreased mortality in such cases.

\section{Materials and methods}

This was a retrospective study performed in a cohort of patients with septic shock admitted to the medical ICU of Samsung Medical Center (a 1,960-bed, universityaffiliated, tertiary referral hospital in Seoul, South Korea), which has 30 beds providing care for approximately 860 critically ill patients per year. The study was approved by the institutional review board of Samsung Medical Center to review and publish information from the patients' records. Informed consent was waived because of the retrospective nature of the study.

\section{Study population}

All consecutive patients with septic shock admitted to the medical ICU between January 2008 and December 2009 were screened for inclusion in this study if they had received low-dose corticosteroid therapy $(\leq 300 \mathrm{mg} /$ day of hydrocortisone or equivalent) for septic shock. Patients were excluded if they were less than 18 years old, had received systemic corticosteroid therapy within the last 3 months before septic shock, had received high-dose steroid therapy (> $300 \mathrm{mg}$ /day of hydrocortisone or equivalent), or did not receive low-dose corticosteroid therapy for septic shock. Additionally, immunocompromised patients, such as those with HIV infection and those who had undergone stem cell or solid organ transplantations, were excluded from the study.

\section{Initial resuscitation and hemodynamic management for septic shock}

A specific protocol for early recognition and management of patients with severe sepsis or septic shock has been implemented in our center since 2004 [13]. Additionally, to improve the compliance with the initial resuscitation bundle and management for sepsis, we revised, approved, and promoted our early goal-directed therapy (EGDT) protocol with an educational program named 'Emergency Approach to Sepsis Treatment (EAST)' in early 2008. Our EGDT protocol is an adaptation of the protocol reported by Rivers et al. [14]. Fluid resuscitation and hemodynamic monitoring were initiated in patients fulfilling the criteria for severe sepsis or septic shock, with placement of a central venous catheter via the internal jugular or subclavian vein approach for central venous pressure (CVP) and central venous oxygen saturation $\left(\mathrm{ScvO}_{2}\right)$ monitoring. Broadspectrum antibiotics were administered as soon as possible. Hemodynamic resuscitation was conducted according to a predetermined treatment plan. First, isotonic crystalloid was administered in boluses to target CVP $\geq$ $8 \mathrm{mmHg}$. Second, systolic blood pressure $\geq 90 \mathrm{mmHg}$ or mean arterial pressure (MAP) $\geq 65 \mathrm{mmHg}$, if not achieved with fluid administration, was targeted by initiating and titrating vasopressors (preferably norepinephrine as a first-line agent) to achieve this desired blood pressure. Finally, $\mathrm{ScvO}_{2} \geq 70 \%$ was targeted after CVP and blood pressure goals were met. If $\mathrm{ScvO}_{2}$ was lower than $70 \%$ and the hematocrit was lower than $30 \%$, packed red blood cells were transfused to achieve a hematocrit of at least $30 \%$. If $\mathrm{ScvO}_{2}$ remained lower than $70 \%$ when hematocrit was $30 \%$ or higher, dobutamine was initiated at the treating physician's discretion and titrated in attempts to reach $\mathrm{ScvO}_{2} \geq 70 \%$. When the patient remained hypotensive after at least one hour of resuscitation with fluids and vasopressor [9], lowdose corticosteroid therapy was recommended as soon as possible after sampling for adrenocorticotropic hormone $(\mathrm{ACTH})$ test if possible. However, the time to initiation of low-dose corticosteroid therapy was decided 
by the treating physician in the emergency department or ICU. Hydrocortisone was administered intravenously every 6 hours as a $50-\mathrm{mg}$ bolus for 5 days and then tapered (50 mg intravenously every 12 hours for 3 days, followed by $50 \mathrm{mg}$ intravenously daily for 3 days). Fludrocortisone was not to be administered in conjunction with hydrocortisone. If hemodynamic stabilization was achieved, the vasopressor was tapered based on the decision of the attending physician, keeping MAP above 65 $\mathrm{mmHg}$ and urinary output higher than $0.5 \mathrm{~mL} / \mathrm{kg} /$ hour.

\section{Definitions}

Septic shock was defined as sepsis with acute circulatory failure characterized by persistent arterial hypotension (systolic arterial pressure $<90 \mathrm{mmHg}$ in 156 patients (88\%), mean arterial pressure $<60 \mathrm{mmHg}$ in $147(83 \%)$, or a reduction in systolic blood pressure $>40 \mathrm{mmHg}$ from baseline in $21(12 \%)$ ) despite adequate volume resuscitation [15]. Organ dysfunction was defined as Sequential Organ Failure Assessment (SOFA) score $\geq 2$ for each organ system $[15,16]$. Critical-illness-related corticosteroid insufficiency (CIRCI) was diagnosed by a delta serum cortisol level of $<9 \mu \mathrm{g} / \mathrm{dL}$ after ACTH $(250$ $\mu \mathrm{g})$ administration (relative adrenal insufficiency) or random total serum cortisol $<10 \mu \mathrm{g} / \mathrm{dL}$ [12]. Appropriate antibiotic therapy was considered if the initially prescribed antibiotics were active against the identified pathogens, based on in vitro susceptibility testing. The time to initiation of antibiotic therapy relative to the onset of septic shock was defined as the time from the initial onset of septic shock-related hypotension to the initiation of antibiotics [17]. Time to initiation of lowdose corticosteroid therapy was defined as the time from the initial onset of septic shock-related hypotension to the initiation of corticosteroid. Reversal of shock was defined as the maintenance of a systolic blood pressure of at least $90 \mathrm{mmHg}$ without vasopressor support for at least 24 hours $[8,10]$.

\section{Data collection}

The following data recorded at the time of initiation of low-dose corticosteroid therapy were collected from the electronic medical records: general characteristics of the patients including demographic data, infection source, laboratory measurements including initial lactate, amount of fluid administered before initiation of vasopressor, doses of vasopressor (norepinephrine or equivalent), and organ dysfunction. The severity of illness was assessed by Simplified Acute Physiology Score 3 (SAPS 3) [18] and SOFA scores [19]. SAPS 3 was calculated as the worst value for that variable during the first one hour of ICU admission, and SOFA scores were calculated from the data on admission. On ICU admission, the following conditions were evaluated: the need for mechanical ventilation and renal replacement therapy, appropriateness of empirical antibiotic therapy, and presence of bacteremia.

The primary outcome was 28 -day mortality. To address the primary research question of whether mortality and time to initiation of low-dose steroid therapy are associated, we considered age, gender, time to initiation of antibiotic therapy and severity of illness as potential confounders $[17,20]$. The secondary outcomes were reversal of shock, ICU mortality, in-hospital mortality and the duration of ICU and hospital stay.

\section{Statistical analysis}

Data are presented as medians and interquartile range (IQR) for continuous variables and as numbers (percentages) for categorical variables. Data were compared using the Mann-Whitney $U$-test for continuous variables and the $\chi^{2}$ or Fisher's exact test for categorical variables. To assess whether there was an association between 28day mortality and the time to initiation of low-dose corticosteroid therapy, the Mantel-Haenszel test was used to examine trends across the quintiles of time.

A logistic regression model was used to adjust for potential confounding factors in the association between the time to initiation of low-dose corticosteroid therapy and 28-day mortality. Three models were constructed: model 1 was adjusted for age and gender, model 2 was additionally adjusted for time to initiation of antibiotic therapy and severity of illness, and model 3 additionally included factors with $P<0.25$ in univariate analysis as confounding factors [21]. Data are presented as odds ratios (OR) with $95 \%$ confidence intervals $(\mathrm{CI})$.

The baseline characteristics and outcome measures of interest were then compared between the patients receiving low-dose corticosteroid therapy within versus after six hours from the initial onset of septic shockrelated hypotension. Kaplan-Meier estimation was used to determine the 90-day survival curves for these two times to initiation of low-dose corticosteroid therapy, which were then compared using the log-rank test for survival data. Statistical analyses were performed using SAS version 9.1 (SAS Institute, Cary, NC), and twosided $P<0.05$ was considered significant.

\section{Results}

Over the study period, a total of 300 patients with septic shock were admitted to the medical ICU. Of these, 112 patients were excluded according to the exclusion criteria: systemic corticosteroid therapy within the last 3 months before septic shock $(n=63)$, high-dose steroid therapy $(n=40)$, and immunocompromised status $(n=$ 9). Moreover, ten patients who were transferred from other hospitals after initiation of vasopressors were also excluded. Finally, 178 patients who received low-dose 
steroid therapy for septic shock were included in this study.

The baseline characteristics of the patients at the time of initiation of low-dose corticosteroid therapy are presented in Table 1 . There were 107 male and 71 female patients, and the median age was 66 (IQR, 54 to 71) years. The median SAPS 3 and SOFA scores on ICU admission were 81 (72 to 90 ) and 11 (9 to 13), respectively. Pneumonia was the most common cause of septic shock ( $n=80,45 \%)$, followed by gastrointestinal tract infection $(n=47,26 \%)$ and urinary tract infection $(n=$ 19, 11\%). Microbiologically proven infection was observed in $58 \%$ of the cohort, and $37 \%$ had proven bloodstream infection. Seventy-nine percent of these patients received appropriate antibiotic treatment. Mechanical ventilation was needed in 124 (70\%) patients, and renal replacement therapy was needed in 58 (33\%) patients on ICU admission. Median dose of vasopressor (norepinephrine or equivalent) at the time of initiation of low-dose corticosteroid therapy was $0.48 \mu \mathrm{g} / \mathrm{kg} /$ minute. ACTH stimulation tests were performed in 96 (54\%) patients, and CIRCI was diagnosed in 78 patients. The number of patients with relative adrenal insufficiency defined by a delta serum cortisol level of $<9 \mu \mathrm{g} / \mathrm{dL}$ after ACTH administration was 71 (91\% of patients with CIRCI). The median time to initiation of low-dose corticosteroid therapy was 8.5 (3.8 to 19.1 ) hours.

Reversal of shock was achieved in $67 \%$ after a median time of 35 (18 to 65) hours of low-dose corticosteroid therapy. Twenty eight-day mortality was $44 \%$. ICU mortality was 43\%, and median length of ICU stay was 6 (3 to 11 ) days. In-hospital mortality was $58 \%$, and median length of hospital stay was 16 (7 to 31) days. Ninety-day mortality was $50 \%$. Twenty eight-day mortality rates according to the time to initiation of low-dose corticosteroid therapy in quintiles are presented in Figure 1. The mortality rates increased significantly with increasing quintiles of time to initiation of low-dose corticosteroid therapy $(P=0.0107$, test for trend).

Univariate comparisons of baseline characteristics at the time of initiation of low-dose corticosteroid therapy between survivors and non-survivors are presented in Table 2. There were no significant differences in age, sex, sites of infection, bacteremia, time to initiation of antibiotic therapy, or appropriate antibiotic treatment between groups. However, mortality was associated with severity of illness and organ failure requiring mechanical support. Median SAPS 3 and SOFA scores were significantly higher in non-survivors than in survivors $(P<0.0001$ and $P=$ 0.0007 , respectively). Median dose of vasopressor at the time of initiation of low-dose corticosteroid therapy was higher in non-survivors compared with survivors $(P<$ $0.0001)$. The need for mechanical ventilation and renal replacement therapy were also greater in non-survivors compared with survivors $(P=0.0001$ and $P<0.0001$, respectively). The median time to initiation of low-dose corticosteroid therapy was significantly shorter in survivors (6.5 hours, IQR 3.6 to 13.9 hours) than in non-survivors (10.4 hours, IQR 5.5 to 23.5 hours) $(P=0.0135)$. Although there was no difference in prevalence of CIRCI ( $81 \%$ in survivors versus $82 \%$ in non-survivors, $P=$ 0.8679 ), the proportion of patients who underwent a reversal of shock within 48 hours after initiation of lowdose corticosteroid therapy was higher in survivors (74\% versus $22 \%$, respectively, $P<0.0001$ ).

The results of multivariate analyses with the logistic regression model are presented in Table 3. Time to initiation of low-dose corticosteroid therapy was associated with crude 28-day mortality (OR 1.015, 95\% CI 1.001 to $1.030, P=0.0483)$. After adjusting for $a$ priori variables of age and gender (model 1 ), and time to initiation of antibiotic therapy and severity of illness (model 2 ), the association remained significant. The final logistic regression model (model 3 ) included the a priori parameters of age, gender, time to initiation of antibiotic therapy, and severity of illness assessed by SAPS 3 as well as other variables with $P$-values less than 0.25 on univariate analysis (Table 2). After adjusting for potential confounding factors, the time to initiation of low-dose corticosteroid therapy was still significantly associated with 28-day mortality (adjusted OR 1.025, 95\% CI 1.007 to $1.044, P=$ $0.0075)$. Other factors independently associated with inhospital mortality were higher SAPS 3 (adjusted OR $1.063,95 \%$ CI 1.029 to $1.098, P=0.0003$ ), higher dose of vasopressor (norepinephrine or equivalent) (adjusted OR $1.921,95 \%$ CI 1.014 to $3.639, P=0.0453$ ) and need for renal replacement therapy (adjusted OR 3.623, 95\% CI 1.635 to $8.026, P=0.0015)$.

Additionally, patients were categorized as early therapy group (low-dose corticosteroid administered within 6 hours from the initial onset of septic shock-related hypotension, $n=66$ ) and late therapy group (low-dose corticosteroid administered after 6 hours from the initial onset of septic shock-related hypotension, $n=112$ ). Both groups had similar characteristics, such as age, sex, severity of illness, sites of infection, bacteremia, time to initiation of antibiotic therapy, appropriate antibiotic treatment, laboratory data, and organ failure, except for need of mechanical ventilation $(P=0.0071)$ (Table 4$)$. Although the proportion of patients who showed reversal of shock rate was similar in both groups $(P=$ $0.0683)$, ICU mortality rate was better in the early-therapy group (32\%) than in the late-therapy group (49\%) $(P$ $=0.0243)$. Finally, the early therapy group had a $37 \%$ lower 28-day mortality rate than the late therapy group (32\% versus $51 \%, P=0.0132$ ) and a similar difference in mortality rate was observed up to 90 days (Table 4 and Figure 2). After adjusting for potential confounding 


\begin{tabular}{|c|c|}
\hline Characteristics & Number (\%) or median (interquartile range) \\
\hline Age, years & $66(54-71)$ \\
\hline Sex, male & $107(60)$ \\
\hline \multicolumn{2}{|l|}{ Severity of illness } \\
\hline SAPS 3 & $81(72-90)$ \\
\hline SOFA & $11(9-13)$ \\
\hline \multicolumn{2}{|l|}{ Site of infection } \\
\hline Lung & $80(45)$ \\
\hline Gastrointestinal tract & $47(26)$ \\
\hline Urinary tract & $19(11)$ \\
\hline Catheter related & $5(3)$ \\
\hline Skin and soft tissue & $6(3)$ \\
\hline Others & $21(12)$ \\
\hline \multicolumn{2}{|l|}{ Acquisition of infection } \\
\hline Community & $129(72)$ \\
\hline Hospital & $49(28)$ \\
\hline \multicolumn{2}{|l|}{ Locale before ICU admission } \\
\hline Emergency department & $119(67)$ \\
\hline General ward & $59(33)$ \\
\hline \multicolumn{2}{|l|}{ Positive culture } \\
\hline At any site & $104(58)$ \\
\hline Gram-positive only & 33/104 (32) \\
\hline Gram-negative only & $55 / 104(53)$ \\
\hline Fungus only & 4/104 (4) \\
\hline Mixed & $12 / 104(12)$ \\
\hline Of blood & $67(37)$ \\
\hline Gram-positive only & $24 / 67(36)$ \\
\hline Gram-negative only & $36 / 67(54)$ \\
\hline Fungus only & 2/67 (3) \\
\hline Mixed & $5 / 67(7)$ \\
\hline Time to initiation of antibiotic therapy, hour & $0(-5.4-1.4)$ \\
\hline Appropriate antibiotics ${ }^{a}$ & $82 / 104(79)$ \\
\hline \multicolumn{2}{|l|}{ Organ failure ${ }^{b}$} \\
\hline Respiratory & $138(78)$ \\
\hline Coagulation & $109(61)$ \\
\hline Liver & $64(36)$ \\
\hline Renal & $67(38)$ \\
\hline Amount of fluid administered before vasopressor, $\mathrm{L}$ & $1.6(1.0-2.2)$ \\
\hline Vasopressor (norepinephrine or equivalent) dose, $\mu \mathrm{g} / \mathrm{kg} / \mathrm{min}$ & $0.48(0.29-0.80)$ \\
\hline Need for mechanical ventilation & $124(70)$ \\
\hline Need for renal replacement therapy & $58(33)$ \\
\hline $\mathrm{CIRCl}^{\mathrm{c}}$ & 78/96 (81) \\
\hline Relative adrenal insufficiency ${ }^{c}$ & $71 / 96(74)$ \\
\hline Time to initiation of low-dose corticosteroid therapy, hour & $8.5(3.8-19.1)$ \\
\hline
\end{tabular}

CIRCI, critical-illness-related corticosteroid insufficiency; SAPS, Simplified Acute Physiology Score; SOFA, Sequential Organ Failure Assessment. ${ }^{a}$ Appropriate antibiotics were based on the site of infection and available cultures.; ${ }^{\text {b}}$ Organ failure was defined as SOFA score of 2 or more per system; ${ }^{\circ}$ Results of adrenocorticotropic hormone test were available for 96 (54\%) patients.

factors, initiation of low-dose corticosteroid therapy more than 6 hours after the onset of septic shock was independently associated with increased 28-day mortality (adjusted OR 2.142, 95\% CI 1.047 to $4.382, P=$ 0.0369) (Table 5).

\section{Discussion}

This is the first study to evaluate the association between early initiation of low-dose corticosteroid therapy and decreased mortality in patients with septic shock. The results of our retrospective cohort study 


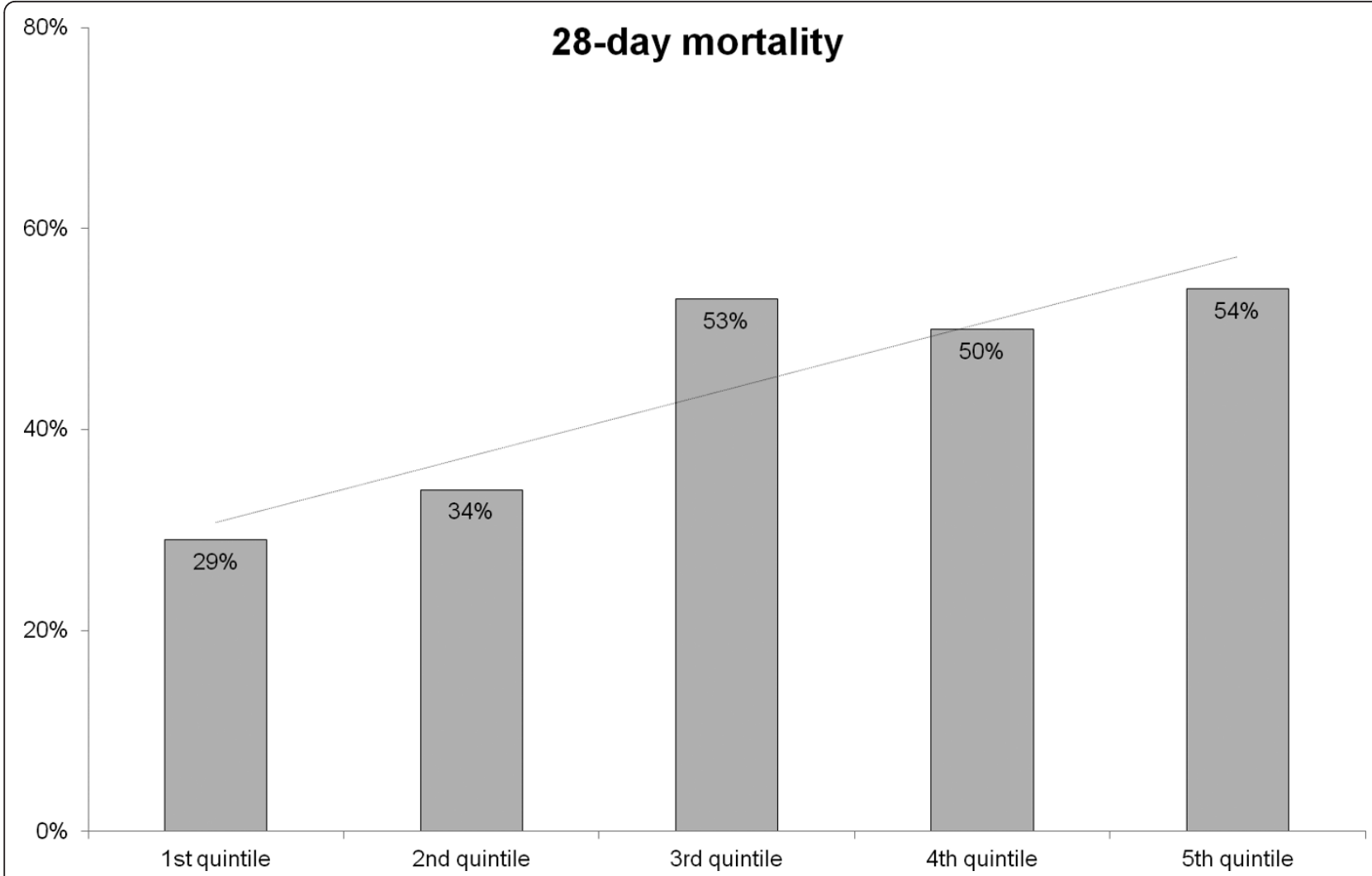

Figure 1 Trend of 28-day mortality rate according to the time to initiation of low-dose corticosteroid therapy in quintiles ( $1^{\text {st }}$ quintile, 0 to 3.0 hours; $2^{\text {nd }}$ quintile, 3.1 to 6.3 hours; $3^{\text {rd }}$ quintile, 6.4 to 11.3 hours; $4^{\text {th }}$ quintile 11.4 to 24.5 hours; $5^{\text {th }}$ quintile, $\geq 24.6$ h) $(P=$ 0.0107 , test for trend).

indicate that early administration of low-dose corticosteroid is independently associated with better outcome in patients with septic shock. Additionally, we found that early low-dose corticosteroid therapy within 6 hours from the initial onset of septic shock-related hypotension reduced the relative risk of 28 -day mortality by $37 \%$ compared with late therapy after 6 hours.

All patients with septic shock in our study received low-dose corticosteroid therapy as a standard treatment protocol. However, time to initiation of this therapy depended on the decision of the primary physician. Therefore, we were able to analyze the association between the time to initiation of low-dose corticosteroid therapy and outcomes. Our findings could partially explain the different results of two large multicenter, randomized, controlled studies of low-dose corticosteroid therapy, which used different time windows of enrollment $[9,10]$. In the study by Annane et al., in which low-dose corticosteroid therapy was initiated within eight hours after the onset of septic shock, a survival benefit was seen in patients with no response to corticotropin [9]. In that study, mean time from initiation of vasopressor to study drug therapy was about four hours. In contrast, because this time window was subsequently increased to 72 hours after the onset of septic shock in the CORTICUS study, the benefit of this therapy was not shown [10]. Although 77\% of enrolled patients were started on the study treatment within 12 hours after the onset of septic shock in the CORTICUS study, there were no significant differences in outcome in this subgroup $[10,22]$. In the present study, the median time to initiation of low-dose corticosteroid therapy was 8.5 hours after the onset of septic shock, and early administration of low-dose corticosteroid was independently associated with decreased mortality even after adjustment for potential confounding factors, including severity of illness, which was another important difference between the two previous large studies. Specifically, when the outcomes were compared between patients treated within six hours after development of septic shock and those treated later, baseline characteristics including severity of illness were not different, but a better outcome was observed in patients receiving low-dose corticosteroid therapy within six hours.

Corticosteroids have potent anti-inflammatory effects and were the first drugs tested in large randomized controlled trials in septic patients [23-25]. However, these studies indicated that a short course of high-dose 
Table 2 Univariate comparisons of baseline characteristics at the time of initiation of low-dose corticosteroid therapy between survivors and non-survivors at 28 days

\begin{tabular}{|c|c|c|c|}
\hline Variables & Survivors (number $=100$ ) & Non-survivors (number $=78$ ) & $P$-value \\
\hline Age, years & $63(54-70)$ & $68(56-74)$ & 0.1115 \\
\hline Sex, male & $59(59)$ & $48(62)$ & 0.7315 \\
\hline \multicolumn{4}{|l|}{ Severity of illness } \\
\hline SAPS 3 & $76(69-87)$ & $85(81-95)$ & $<0.0001$ \\
\hline SOFA & $10(8-12)$ & $12(10-15)$ & 0.0007 \\
\hline Site of infection & & & 0.5389 \\
\hline Lung & $44(44)$ & $36(46)$ & \\
\hline Gastrointestinal tract & $24(24)$ & $23(30)$ & \\
\hline Urinary tract & $14(14)$ & $5(6)$ & \\
\hline Catheter related & 0 & $5(6)$ & \\
\hline Skin and soft tissue & $4(4)$ & $2(3)$ & \\
\hline Others & $14(14)$ & $7(9)$ & \\
\hline Bacteremia & $35(34)$ & $32(41)$ & 0.4103 \\
\hline Time to initiation of antibiotic therapy, hour & $-0.2(-5.2-1.3)$ & $-0.4(-3.1-2.1)$ & 0.3977 \\
\hline Appropriate antibiotics ${ }^{a}$ & $52 / 61(85)$ & $30 / 43(70)$ & 0.057 \\
\hline \multicolumn{4}{|l|}{ Laboratory data } \\
\hline Leukocytes, $10^{3} / \mathrm{mm}^{3}$ & $8.8(1.6-19.9)$ & $7.9(0.3-17.0)$ & 0.2221 \\
\hline Platelet, $10^{3} / \mathrm{mm}^{3}$ & $88(43-179)$ & $65(35-102)$ & 0.0235 \\
\hline Total bilirubin, mg/dL & $1.4(0.8-2.5)$ & $1.4(0.9-3.7)$ & 0.3359 \\
\hline Creatinine, mg/dL & $1.3(0.9-2.1)$ & $1.7(1.0-2.9)$ & 0.1326 \\
\hline Prothrombin time, $\%$ & $61(47-68)$ & $53(41-65)$ & 0.058 \\
\hline Albumin & $2.9(2.5-3.3)$ & $2.6(2.3-3.0)$ & 0.0083 \\
\hline Initial lactate, mmol/L & $3.7(2.6-5.5)$ & $4.3(2.9-9.6)$ & 0.0382 \\
\hline \multicolumn{4}{|l|}{ Organ failure $\mathrm{e}^{\mathrm{b}}$} \\
\hline Respiratory & $71(71)$ & $67(86)$ & 0.0181 \\
\hline Coagulation & $51(51)$ & $58(74)$ & 0.0015 \\
\hline Liver & $34(34)$ & $30(39)$ & 0.5383 \\
\hline Renal & $29(29)$ & $38(49)$ & 0.0071 \\
\hline Amount of fluid administered before vasopressor, $L$ & $1.5(1.0-2.3)$ & $1.6(1.1-2.2)$ & 0.263 \\
\hline Vasopressor (norepinephrine or equivalent) dose, $\mu \mathrm{g} / \mathrm{kg} / \mathrm{min}$ & $0.36(0.19-0.61)$ & $0.67(0.43-1.16)$ & $<0.0001$ \\
\hline Need for mechanical ventilation & $58(58)$ & $66(85)$ & 0.0001 \\
\hline Need for renal replacement therapy & $18(18)$ & $40(51)$ & $<0.0001$ \\
\hline $\mathrm{CIRCl}^{\mathrm{c}}$ & $46 / 57(81)$ & $32 / 39(82)$ & 0.8679 \\
\hline Relative adrenal insufficiency ${ }^{c}$ & $41 / 57(72)$ & $30 / 39(77)$ & 0.584 \\
\hline Time to initiation of low-dose corticosteroid therapy, hour & $6.5(3.6-13.9)$ & $10.4(5.5-23.3)$ & 0.0135 \\
\hline
\end{tabular}

95\% Cl, 95\% confidence interval; CIRCl, critical-illness-related corticosteroid insufficiency; HR, hazard ratio; SAPS, Simplified Acute Physiology Score; SOFA,

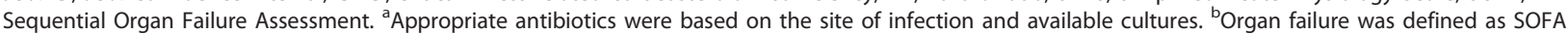

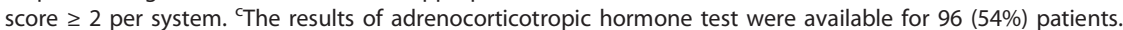

Table 3 Associations between the time to initiation of low-dose corticosteroid therapy and 28-day mortality after adjustments for potential confounding factors

\begin{tabular}{|c|c|c|c|c|c|}
\hline \multirow[t]{2}{*}{ Time to initiation of low-dose corticosteroid therapy (hour) } & \multicolumn{5}{|c|}{ Variables in the equation } \\
\hline & Coefficient & SE & $P$-value & OR & $95 \% \mathrm{Cl}$ \\
\hline Crude state & 0.0147 & 0.0074 & 0.0483 & 1.015 & $1.001-1.030$ \\
\hline \multicolumn{6}{|l|}{ Adjusted state ${ }^{a}$} \\
\hline Model 1 & 0.0147 & 0.0074 & 0.0483 & 1.015 & $1.001-1.030$ \\
\hline Model 2 & 0.0239 & 0.0088 & 0.0065 & 1.024 & $1.007-1.042$ \\
\hline Model 3 & 0.0249 & 0.0093 & 0.0075 & 1.025 & $1.007-1.044$ \\
\hline
\end{tabular}

95\% Cl, 95\% confidence interval; OR, odds ratio; SE, standard error. ${ }^{\mathrm{a}}$ Model 1 was adjusted for age and gender. Model 2 was additionally adjusted for SAPS 3 and time to initiation of antibiotic therapy. Model 3 additionally included leukocytes, platelet, creatinine, prothrombin time, albumin, initial lactate, vasopressor dose, the need for mechanical ventilation and continuous renal replace therapy. 
Table 4 Baseline characteristics, therapy, and outcomes between early ( $\leq 6$ hour) and late ( $>6$ hour) low-dose corticosteroid therapy groups

\begin{tabular}{|c|c|c|c|}
\hline Variables & $\begin{array}{l}\text { Early group, } \leq 6 \text { hour (number }= \\
66 \text { ) }\end{array}$ & $\begin{array}{l}\text { Late group, }>6 \text { hour (number }= \\
112 \text { ) }\end{array}$ & $\begin{array}{l}P \text { - } \\
\text { value }\end{array}$ \\
\hline Age, years & $67(55-71)$ & $65(53-71)$ & 0.8142 \\
\hline Sex, male & $42(64)$ & $65(58)$ & 0.4611 \\
\hline \multicolumn{4}{|l|}{ Severity of illness } \\
\hline SAPS 3 & $80(71-89)$ & $82(72-91)$ & 0.146 \\
\hline SOFA & $11(9-13)$ & $11(9-14)$ & 0.6498 \\
\hline Site of infection & & & 0.7997 \\
\hline Lung & $27(41)$ & $53(47)$ & \\
\hline Gastrointestinal tract & $20(30)$ & $27(24)$ & \\
\hline Urinary tract & $9(14)$ & $10(9)$ & \\
\hline Catheter related & $3(4)$ & $2(2)$ & \\
\hline Skin and soft tissue & $1(2)$ & $5(4)$ & \\
\hline Others & $6(9)$ & $15(14)$ & \\
\hline Bacteremia & $28(42)$ & $39(35)$ & 0.3119 \\
\hline Time to initiation of antibiotic therapy, hour & $0.1(-3.3-1.2)$ & $0.1(-4.9-1.9)$ & 0.9659 \\
\hline Appropriate antibiotics ${ }^{\mathrm{a}}$ & $36 / 42(86)$ & $46 / 62(74)$ & 0.1581 \\
\hline \multicolumn{4}{|l|}{ Laboratory data } \\
\hline Leukocytes, $10^{3} / \mathrm{mm}^{3}$ & $6.9(0.3-16.5)$ & $10.2(0.1-18.1)$ & 0.1797 \\
\hline Platelet, $10^{3} / \mathrm{mm}^{3}$ & $75(35-148)$ & $68(40-155)$ & 0.5662 \\
\hline Total bilirubin, mg/dL & $1.4(0.9-2.7)$ & $1.4(0.9-1.7)$ & 0.9519 \\
\hline Creatinine, mg/dL & $1.7(1.0-2.5)$ & $1.4(0.9-2.4)$ & 0.1673 \\
\hline Prothrombin time, s & $61(47-68)$ & $54(42-66)$ & 0.2931 \\
\hline Albumin, $\mathrm{g} / \mathrm{dL}$ & $3.0(2.3-3.3)$ & $2.6(2.4-3.1)$ & 0.0811 \\
\hline Initial lactate, $\mathrm{mmol} / \mathrm{L}$ & $4.1(2.8-5.7)$ & $3.8(2.6-6.6)$ & 0.8798 \\
\hline \multicolumn{4}{|l|}{ Organ failure ${ }^{\mathrm{b}}$} \\
\hline Respiratory & $48(73)$ & $90(80)$ & 0.2388 \\
\hline Coagulation & $43(65)$ & $66(59)$ & 0.4105 \\
\hline Liver & $24(36)$ & $40(36)$ & 0.9305 \\
\hline Renal & $28(42)$ & $39(35)$ & 0.3119 \\
\hline Amount of fluid administered before vasopressor, $\mathrm{L}$ & $1.6(1.0-2.3)$ & $1.5(1.1-2.2)$ & 0.1932 \\
\hline $\begin{array}{l}\text { Vasopressor (norepinephrine or equivalent) dose, } \mu \mathrm{g} / \mathrm{kg} / \\
\min \end{array}$ & $0.50(0.32-1.06)$ & $0.52(0.29-0.80)$ & 0.6277 \\
\hline Need for mechanical ventilation & $38(58)$ & $86(77)$ & 0.0071 \\
\hline Need for renal replacement therapy & $19(29)$ & $39(35)$ & 0.4068 \\
\hline $\mathrm{CIRCl}^{\mathrm{C}}$ & $16 / 23(70)$ & $62 / 73(85)$ & 0.1269 \\
\hline Relative adrenal insufficiency ${ }^{c}$ & $15 / 23(65)$ & $56 / 73(77)$ & 0.2733 \\
\hline \multicolumn{4}{|l|}{ Outcomes } \\
\hline Reversal of shock & $50(76)$ & $70(63)$ & 0.0683 \\
\hline ICU mortality & $21(32)$ & $55(49)$ & 0.0243 \\
\hline Length of stay in ICU, days & $4(3-8)$ & $7(4-12)$ & 0.004 \\
\hline 28-day mortality & $21(32)$ & $57(51)$ & 0.0132 \\
\hline 90-day mortality & $27(41)$ & $72(64)$ & 0.0024 \\
\hline In-hospital mortality & $29(44)$ & $75(67)$ & 0.0026 \\
\hline Length of stay in hospital, days & $16(7-28)$ & $18(7-30)$ & 0.6974 \\
\hline
\end{tabular}

CIRCI, critical-illness-related corticosteroid insufficiency; SAPS, Simplified Acute Physiology Score; SOFA, Sequential Organ Failure Assessment. ${ }^{a}$ Appropriate

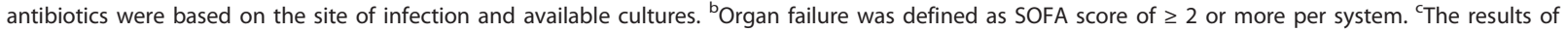
adrenocorticotropic hormone test were available for 96 (54\%) patients. 


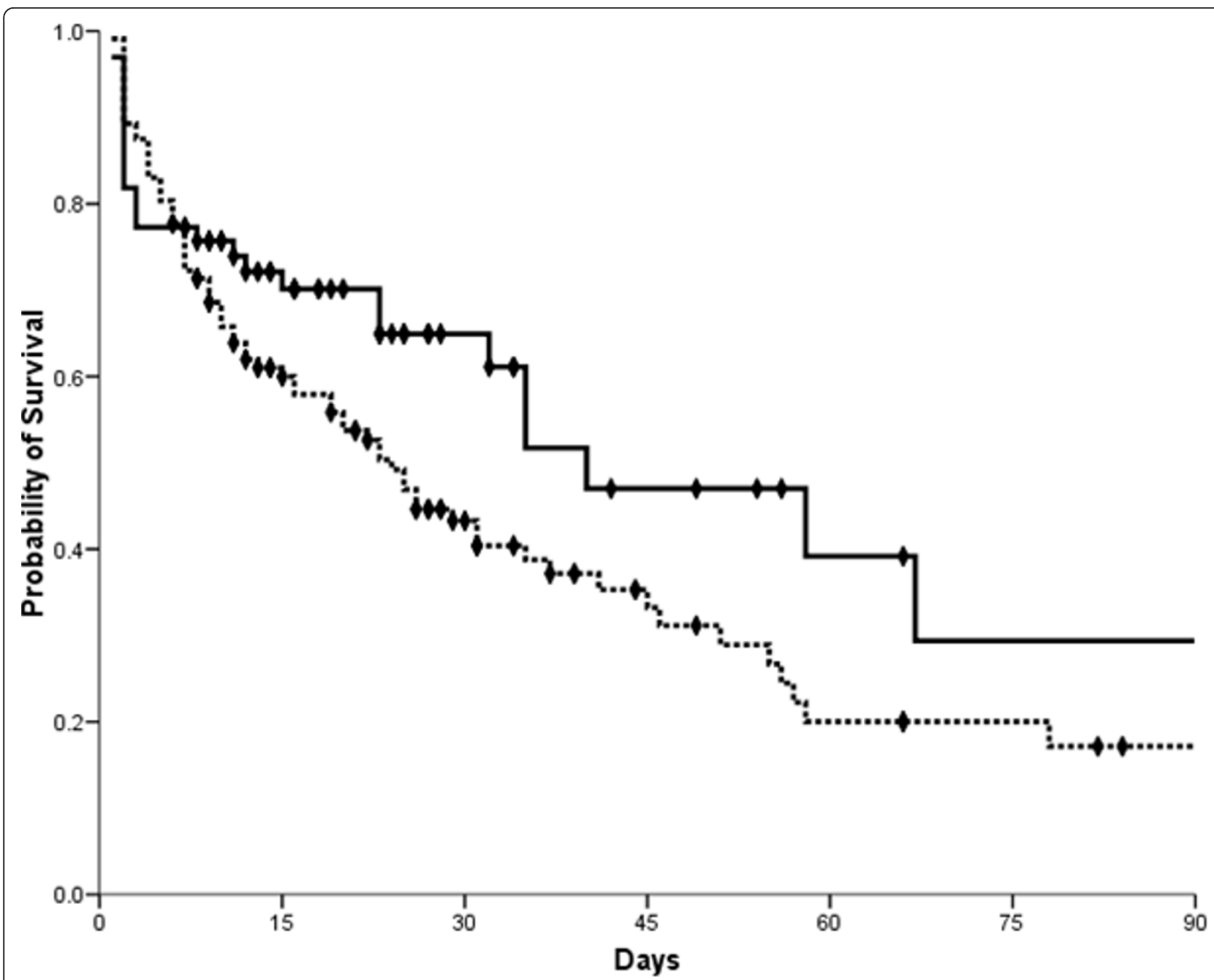

Figure 2 Kaplan-Meier survival analysis comparing patients treated with low-dose corticosteroid therapy within six hours after development of septic shock and those treated later (solid line represents the early therapy group, who received the therapy within six hours; dotted line represents the late therapy group, who received the therapy after six hours).

corticosteroid in early stages of septic shock had no effect on outcome or was even harmful, probably because of immunosuppression and increased incidence of secondary infections [5-7]. Only one study showed an initial improvement in survival and shock reversal with high-dose corticosteroid, but with ongoing disease, the difference was no longer significant [23]. Recently, the observation that severe sepsis and septic shock may be associated with absolute or relative adrenal insufficiency and steroid receptor resistance prompted renewed interest in steroid treatment in septic patients [26,27]. A novel approach of low-dose corticosteroid was found to have beneficial effects on hemodynamics and outcome [7-9]. These effects have mainly been attributed to sensitization of the vasculature to vasopressor [28]. However, there is other evidence that this low-dose corticosteroid therapy affects the immune response [29-31]. Briegel et al. [29] reported that low-dose corticosteroid therapy

Table 5 Multivariate analysis with forward stepwise multiple logistic regression model for probability of 28-day mortality in patients receiving low-dose corticosteroid therapy

\begin{tabular}{llll}
\hline Variables & Adjusted OR & 95\% Cl & $P$-value \\
\hline SAPS 3 & 1.059 & $1.028-1.091$ & 0.0001 \\
Need for renal replacement therapy & 4.191 & $2.026-8.668$ & 0.0369 \\
Late (> 6 hour) low-dose corticosteroid therapy & 2.142 & $1.047-4.382$ & 0.0369 \\
\hline
\end{tabular}

95\% Cl, 95\% confidence interval; OR, odds ratio; SAPS, Simplified Acute Physiology Score. 
was associated with significant reductions in proinflammatory cytokine levels and with early resolution of sepsis-induced organ dysfunction. Keh et al. [30] also demonstrated that low-dose corticosteroid therapy inhibited systemic inflammation and prevented overwhelming compensatory anti-inflammatory responses. Moreover, in a recent randomized controlled study, Oppert et al. [31] found that the anti-inflammatory effects of low-dose corticosteroid were independent of adrenal function. Therefore, if the benefits of low-dose corticosteroid therapy in the management of septic shock are not limited to hemodynamic improvement in patients with impaired adrenal functions but are also related to anti-inflammatory effects, timely initiation of this treatment would be important. Unfortunately, our study has no data related to the anti-inflammatory effects of low-dose corticosteroid therapy.

Several reports provided additional evidence of the importance of timely intervention in the management of septic shock. Rivers et al. [14] reported that early hemodynamic resuscitation (EGDT) for severe sepsis and septic shock within six hours resulted in improved survival compared with less prompt resuscitation treatment. Kumar et al. [17] showed that from the onset of hypotension in patients with septic shock, each hour of delay in antibiotic therapy over the ensuing six hours was associated with an increase in mortality. In the present study, initiation of low-dose corticosteroid therapy more than six hours after the onset of septic shock was independently associated with increased mortality after adjusting for potential confounding factors.

To fully appreciate these results, the limitations of this study must be acknowledged. First, given its retrospective nature, there is always the possibility that selection bias may have influenced the significance of our findings. Previous observational studies reported that patients treated with low-dose corticosteroids are more severely ill $[32,33]$. Therefore, more severely ill patients might receive delayed initiation of low-dose corticosteroid therapy compared to patients who received early therapy in this study. However, baseline severity or number of organ failures at the time of initiation of low-dose corticosteroid therapy was not different between the early treatment group and the late treatment group. In addition, adjusted multivariate analysis, and the protocolization of initial resuscitation and management for severe sepsis and septic shock before the initiation of this study served to minimize the potential for selection bias. However, the potential for a bias of unmeasured confounder remains. Second, the data on initial resuscitation could not be extracted due to incomplete medical records. Compliance with initial resuscitation bundles and achievement of end points may be important confounding factors in the association between time to initiation of low-dose corticosteroid therapy and mortality. Other data of our EAST program on the initial resuscitation for severe sepsis and septic shock in the emergency department for one year (from August, 2008 to July, 2009) noted that compliance of resuscitation bundle was 50\% (unpublished data). However, it is not clear how compliance with EGDT and achievement of end points would affect this association. Furthermore, there are potential barriers to the effective implementation of EGDT at the patient, clinician, and organizational level [34]. Therefore, our results represent actual practice at a tertiary referral hospital. Third, the reason for delayed initiation of low-dose corticosteroid therapy could not be evaluated.

\section{Conclusions}

The results of this study demonstrated a significant association between early initiation of low-dose corticosteroid therapy and decreased mortality rate in patients with septic shock. However, this observation needs further evaluation with a prospective, randomized, controlled study.

\section{Key messages}

- Early initiation of low-dose corticosteroid therapy is significantly associated with decreased mortality in patients with septic shock.

- Additionally, early low-dose corticosteroid therapy within 6 hours from the initial onset of septic shockrelated hypotension reduced the relative risk of 28day mortality by $37 \%$ compared with late therapy after 6 hours from the hypotension.

\section{Abbreviations}

ACTH: adrenocorticotropic hormone; Cl: confidence intervals; CIRCl: criticalillness-related corticosteroid insufficiency; CVP: central venous pressure;

EGDT: early goal-directed therapy; HR: hazard ratios; IQR: interquartile range; MAP: mean arterial pressure; SAP 3: Simplified Acute Physiology Score 3; $\mathrm{SCVO}_{2}$ : central venous oxygen saturation; SOFA: Sequential Organ Failure Assessment.

\section{Acknowledgements}

The authors thank Dr. Seonwoo Kim, PhD, at Samsung Biomedical Research Institute for comments regarding statistical analysis.

This work was supported by a grant from the IN-SUNG Foundation for Medical Research (CA98071).

\section{Author details}

${ }^{1}$ Division of Pulmonary and Critical Care Medicine, Department of Medicine, Samsung Medical Center, Sungkyunkwan University School of Medicine, 81 Irwon-ro, Gangnam-gu, Seoul, 135-710, Republic of Korea. ${ }^{2}$ Department of Emergency Medicine, Samsung Medical Center, Sungkyunkwan University School of Medicine, 81 Irwon-ro, Gangam-gu, Seoul, 135-710, Republic of Korea. ${ }^{3}$ Biostatistics Team, Samsung Biomedical Research Institute, 81 Irwonro, Gangnam-gu, Seoul, 135-710, Republic of Korea.

\section{Authors' contributions}

HYP collected and analyzed the data and drafted this manuscript. GYS contributed to the design of this study, analysis of the data, and writing of the manuscript. JS collected data and assisted with analyzing the data and 
drafting the manuscript. HY collected data and assisted with analyzing the data and revising the manuscript. IJJ contributed to analysis and interpretation of data and revising the manuscript. TGS collected data and assisted with analyzing the data and drafting the manuscript. SYL collected data and assisted with analyzing the data and drafting the manuscript. SW conducted statistical analyses and interpreted the data. $\mathrm{KJ}$ conceived and designed the study, analyzed the data, and wrote the final manuscript. All authors have read and approved the final manuscript.

\section{Competing interests}

The authors declare that they have no competing interests.

Received: 16 October 2011 Revised: 6 December 2011

Accepted: 7 January 2012 Published: 7 January 2012

\section{References}

1. Angus DC, Linde-Zwirble WT, Lidicker J, Clermont G, Carcillo J, Pinsky MR: Epidemiology of severe sepsis in the United States: analysis of incidence, outcome, and associated costs of care. Crit Care Med 2001, 29:1303-1310.

2. Angus DC, Pereira CA, Silva E: Epidemiology of severe sepsis around the world. Endocr Metab Immune Disord Drug Targets 2006, 6:207-212

3. Dellinger RP, Levy MM, Carlet JM, Bion J, Parker MM, Jaeschke R, Reinhart K, Angus DC, Brun-Buisson C, Beale R, Calandra T, Dhainaut JF, Gerlach H, Harvey M, Marini JJ, Marshall J, Ranieri M, Ramsay G, Sevransky J, Thompson BT, Townsend S, Vender JS, Zimmerman JL, Vincent JL: Surviving Sepsis Campaign: international guidelines for management of severe sepsis and septic shock: 2008. Crit Care Med 2008, 36:296-327.

4. Sweeney DA, Danner RL, Eichacker $P Q$, Natanson C: Once is not enough: clinical trials in sepsis. Intensive Care Med 2008, 34:1955-1960.

5. Lefering R, Neugebauer EA: Steroid controversy in sepsis and septic shock: a meta-analysis. Crit Care Med 1995, 23:1294-1303.

6. Cronin L, Cook DJ, Carlet J, Heyland DK, King D, Lansang MA, Fisher CJ Jr: Corticosteroid treatment for sepsis: a critical appraisal and meta-analysis of the literature. Crit Care Med 1995, 23:1430-1439.

7. Briegel J, Forst H, Haller M, Schelling G, Kilger E, Kuprat G, Hemmer B, Hummel T, Lenhart A, Heyduck M, Stoll C, Peter K: Stress doses of hydrocortisone reverse hyperdynamic septic shock: a prospective, randomized, double-blind, single-center study. Crit Care Med 1999, 27:723-732.

8. Bollaert PE, Charpentier C, Levy B, Debouverie M, Audibert G, Larcan A: Reversal of late septic shock with supraphysiologic doses of hydrocortisone. Crit Care Med 1998, 26:645-650.

9. Annane D, Sebille V, Charpentier C, Bollaert PE, Francois B, Korach JM, Capellier G, Cohen Y, Azoulay E, Troche G, Chaumet-Riffaud P, Bellissant E: Effect of treatment with low doses of hydrocortisone and fludrocortisone on mortality in patients with septic shock. JAMA 2002, 288:862-871.

10. Sprung $C L$, Annane $D$, Keh D, Moreno R, Singer M, Freivogel K, Weiss YG, Benbenishty J, Kalenka A, Forst H, Laterre PF, Reinhart K, Cuthbertson BH, Payen D, Briegel J: Hydrocortisone therapy for patients with septic shock. N Engl J Med 2008, 358:111-124.

11. Annane D, Bellissant $E$, Bollaert PE, Briegel J, Keh D, Kupfer $Y$ : Corticosteroids for severe sepsis and septic shock: a systematic review and meta-analysis. BMJ 2004, 329:480.

12. Marik PE, Pastores SM, Annane D, Meduri GU, Sprung CL, Arlt W, Keh D, Briegel J, Beishuizen A, Dimopoulou I, Tsagarakis S, Singer M, Chrousos GP, Zaloga G, Bokhari F, Vogeser M: Recommendations for the diagnosis and management of corticosteroid insufficiency in critically ill adult patients: consensus statements from an international task force by the American College of Critical Care Medicine. Crit Care Med 2008, 36:1937-1949.

13. Dellinger RP, Carlet JM, Masur H, Gerlach H, Calandra T, Cohen J, GeaBanacloche J, Keh D, Marshall JC, Parker MM, Ramsay G, Zimmerman JL, Vincent $J$, Levy MM: Surviving Sepsis Campaign guidelines for management of severe sepsis and septic shock. Crit Care Med 2004, 32:858-873.

14. Rivers E, Nguyen B, Havstad S, Ressler J, Muzzin A, Knoblich B, Peterson E, Tomlanovich M: Early goal-directed therapy in the treatment of severe sepsis and septic shock. N Engl J Med 2001, 345:1368-1377.

15. Levy MM, Fink MP, Marshall JC, Abraham E, Angus D, Cook D, Cohen J, Opal SM, Vincent JL, Ramsay G: 2001 SCCM/ESICM/ACCP/ATS/SIS
International Sepsis Definitions Conference. Crit Care Med 2003, 31:1250-1256

16. Park MR, Jeon K, Song JU, Lim SY, Park SY, Lee JE, Huh W, Kim K, Kim WS, Jung CW, Suh GY: Outcomes in critically ill patients with hematologic malignancies who received renal replacement therapy for acute kidney injury in an intensive care unit. J Crit Care 2011, 26:107.e101-107.e106.

17. Kumar A, Roberts D, Wood KE, Light B, Parrillo JE, Sharma S, Suppes R, Feinstein D, Zanotti S, Taiberg L, Gurka D, Cheang M: Duration of hypotension before initiation of effective antimicrobial therapy is the critical determinant of survival in human septic shock. Crit Care Med 2006, 34:1589-1596.

18. Moreno RP, Metnitz PG, Almeida E, Jordan B, Bauer P, Campos RA, lapichino G, Edbrooke D, Capuzzo M, Le Gall JR: SAPS 3-From evaluation of the patient to evaluation of the intensive care unit. Part 2: Development of a prognostic model for hospital mortality at ICU admission. Intensive Care Med 2005, 31:1345-1355.

19. Vincent JL, Moreno R, Takala J, Willatts S, De Mendonca A, Bruining H, Reinhart CK, Suter PM, Thijs LG: The SOFA (Sepsis-related Organ Failure Assessment) score to describe organ dysfunction/failure. On behalf of the Working Group on Sepsis-Related Problems of the European Society of Intensive Care Medicine. Intensive Care Med 1996, 22:707-710.

20. Shapiro N, Howell MD, Bates DW, Angus DC, Ngo L, Talmor D: The association of sepsis syndrome and organ dysfunction with mortality in emergency department patients with suspected infection. Ann Emerg Med 2006, 48:583-590, 590.e1.

21. Mickey RM, Greenland S: The impact of confounder selection criteria on effect estimation. Am J Epidemiol 1989, 129:125-137.

22. Finfer S: Corticosteroids in septic shock. N Engl J Med 2008, 358:188-190.

23. Sprung $C L$, Caralis PV, Marcial EH, Pierce M, Gelbard MA, Long WM, Duncan RC, Tendler MD, Karpf M: The effects of high-dose corticosteroids in patients with septic shock. A prospective, controlled study. N Engl J Med 1984, 311:1137-1143.

24. Effect of high-dose glucocorticoid therapy on mortality in patients with clinical signs of systemic sepsis. The Veterans Administration Systemic Sepsis Cooperative Study Group. N Engl J Med 1987, 317:659-665.

25. Bone RC, Fisher CJ Jr, Clemmer TP, Slotman GJ, Metz CA, Balk RA: A controlled clinical trial of high-dose methylprednisolone in the treatment of severe sepsis and septic shock. N Engl J Med 1987 317:653-658.

26. Rothwell PM, Udwadia ZF, Lawler PG: Cortisol response to corticotropin and survival in septic shock. Lancet 1991, 337:582-583.

27. Cooper MS, Stewart PM: Corticosteroid insufficiency in acutely ill patients. N Engl J Med 2003, 348:727-734.

28. Annane D, Bellissant E, Sebille V, Lesieur O, Mathieu B, Raphael JC, Gajdos P. Impaired pressor sensitivity to noradrenaline in septic shock patients with and without impaired adrenal function reserve. Br J Clin Pharmacol 1998, 46:589-597.

29. Briegel J, Jochum M, Gippner-Steppert C, Thiel M: Immunomodulation in septic shock: hydrocortisone differentially regulates cytokine responses. J Am Soc Nephrol 2001, 12(Suppl 17):S70-74.

30. Keh D, Boehnke T, Weber-Cartens S, Schulz C, Ahlers O, Bercker S, Volk HD Doecke WD, Falke K, Gerlach H: Immunologic and hemodynamic effects of "low-dose" hydrocortisone in septic shock: a double-blind, randomized, placebo-controlled, crossover study. Am J Respir Crit Care Med 2003, 167:512-520.

31. Oppert M, Schindler R, Husung C, Offermann K, Graf KJ, Boenisch O, Barckow D, Frei U, Eckardt KU: Low-dose hydrocortisone improves shock reversal and reduces cytokine levels in early hyperdynamic septic shock. Crit Care Med 2005, 33:2457-2464.

32. Levy H, Laterre PF, Bates B, Qualy RL: Steroid use in PROWESS severe sepsis patients treated with drotrecogin alfa (activated). Crit Care 2005, 9: R502-507.

33. Beale R, Janes JM, Brunkhorst FM, Dobb G, Levy MM, Martin GS, Ramsay G, Silva $E$, Sprung $C L$, Vallet $B$, Vincent $J$, Costigan TM, Leishman AG, Williams MD, Reinhart K: Global utilization of low-dose corticosteroids in severe sepsis and septic shock: a report from the PROGRESS registry. Crit Care 2010, 14:R102.

34. Mikkelsen ME, Gaieski DF, Goyal M, Miltiades AN, Munson JC, Pines JM, Fuchs BD, Shah CV, Bellamy SL, Christie JD: Factors associated with nonadherence to early goal-directed therapy in the ED. Chest 2010, 138:551-558. 


\section{doi:10.1186/cc10601}

Cite this article as: Park et al:: Early initiation of low-dose corticosteroid

therapy in the management of septic shock: a retrospective

observational study. Critical Care 2012 16:R3.

Submit your next manuscript to BioMed Central and take full advantage of:

- Convenient online submission

- Thorough peer review

- No space constraints or color figure charges

- Immediate publication on acceptance

- Inclusion in PubMed, CAS, Scopus and Google Scholar

- Research which is freely available for redistribution

Submit your manuscript at 